\title{
PRODUCTION OF PEPTIDE ANTIBIOTICS BY BACILLUS SP. GU 057 INDIGENOUSLY ISOLATED FROM
} SALINE SOIL

\author{
Adnan Amin ${ }^{1 *}$, Muhammad Ayaz Khan ${ }^{1}$, Malik Ehsanullah', Uzma Haroon², Sheikh Muhammad Farooq Azam², Abdul \\ Hameed $^{3}$ \\ ${ }^{1}$ Gomal Centre of Biochemistry and Biotechnology (GCBB) Gomal University, D.I.Khan (KPK), Pakistan; ${ }^{2}$ Chemistry \\ Department, Gomal University, D.I.Khan (KPK) Pakistan; ${ }^{3}$ Department of Microbiology, Faculty of Biological Sciences, Quaid I \\ Azam University, Islamabad Pakistan.
}

Submitted: September 16, 2011; Returned to authors for corrections: February 15, 2012; Approved: June 07, 2012.

\begin{abstract}
A total of 112 soil samples were taken from differents areas of district D.I.Khan and Kohat (KPK) Pakistan and screened for production of antibiotics against the Micrococcus luteus and Staphylococcus aureus. Widest zone of inhibition $(18 \mathrm{~mm})$ was produced by microorganism isolated from saline soil. The strain was later identified as Bacillus GU057 by standard biochemical assays. Maximum activity (18mm inhibition zone) was observed against Staphylococcus aureus after 48 hours of incubation at $\mathrm{pH} 8$ and $4 \%$ concentration of glucose. The antibiotic was identified by autobiography as bacitracin. The Bacillus strain GU057 was confirmed as good peptide antibiotic producer and can effectively be indulged as biocontrol agent.
\end{abstract}

Key words: Peptide antibiotics, Bacillus species, screening, optimization of parameters.

\section{INTRODUCTION}

Antibiotics are the secondary metabolites produced by the microorganisms via enzymatic catalysis involving a series of biosynthetic pathways (9). Naturally the antibiotics produced by microorganisms are responsible for the regulation and control of microbial population in soil, compost and water. Majority of such antibiotics are toxic in nature and only few find a use in medicine for treatment of multiple ailments due to high margin of safety $(7,27)$. Such antibiotics are mainly produced by Penicillium, Streptomyces, Cephalosporium,
Micomonospora and Bacillus accounting for more than 5,000 compounds $(4,26)$. These antibiotics are low molecular weight polypeptides produced by ribosomal or non ribosomal mechanisms (17).

The Bacillus species are known for the synthesis of secondary metabolites with remarkable diversity both in structure and function (22). For instance cerecin 7, Tochicin, Thuricin 7, thuricin 439 and entomocidus $9(7,8)$ and few may be ribosomal in origin including sublancin (18), subtilosin A (3), subtilin (27) and TasA (24) are highly active against variety of microorganisms (10). 
Bacitracin is most important cyclic polypeptide antibiotic produced Bacillus species and is primarily active against the Gram-positive bacteria. The bacitracin is used as anti-infective agent in a variety of pharmaceutical preparations including aerosols, topical lotions, skin ointments and creams $(2,25)$. The bactericidal activity of bacitracin is the result of cell wall inhibition.

The purpose of this study was to isolate antibiotic producing Bacillus strain from extreme conditions (saline soil) and suggest the optimum conditions for maximum activity.

\section{MATERIALS AND METHODS}

\section{Screening of antibiotic-producing Bacillus species from soil}

About 112 soil samples were taken from different locations of district D.I.Khan and Kohat (KPK) Pakistan and assessed for antimicrobial potential. The lawn of test strains Staphylococcus aureus and Micrococcus luteus was applied gently on surface of freshly prepared Muller Hinton agar (oxoid) plates and was sprinkled with 10-25 particles of each soil sample separately. These agar plates were incubated at $30^{\circ} \mathrm{C}$ for 24 to 48 hours. After incubation, the plates were observed for antimicrobial activity by observing the zones of inhibition around microbial colonies (2).These microbial colonies were picked up by a sterilized wire loop and subcultured many times to obtain isolated and purified bacterial colonies.

\section{Antibiotic production}

The bacterial isolates with widest zone of inhibition was inoculated in the Muller Hinton (Oxoid) broth at $\mathrm{pH} 7.3$ in a flask and incubated for $48-72$ hours at $150 \mathrm{rpm}$ at $30^{\circ} \mathrm{C}$. Sterilized production medium was prepared according to instructions (2) (Table 1). The inoculum was shifted to the production medium and incubated for 192 hours at 150rpm in an orbital shaker. After every 24 hours, samples were drawn up to 192 hours. Each sample was centrifuged separately to obtain cell-free culture supernatant followed by sterilization through $0.2 \mu \mathrm{m}$. filter paper. The supernatant so obtained was subjected to agar well diffusion assay for antibiotic production. Similar procedure was repeated for the optimization of the identified Bacillus specie at various $\mathrm{pH}$, temperature and glucose concentrations (optimization parameters) and results were recorded.

Table 1. Composition of production medium (g/L).

\begin{tabular}{ll}
\hline \multicolumn{1}{c}{ Contents } & Quantity \\
\hline L-Glutamic acid & 5.0 \\
MgSO $4.7 \mathrm{H} 2$ & 0.2 \\
$\mathrm{MnSO} 4 . \mathrm{H} 2 \mathrm{O}$ & 0.01 \\
$\mathrm{NaCl}$ & 0.01 \\
$\mathrm{FeSO} 4.7 \mathrm{H} 2 \mathrm{O}$ & 0.01 \\
$\mathrm{CuSO} 4.2 \mathrm{H} 2 \mathrm{O}$ & 0.01 \\
$\mathrm{CaCl}_{2} .2 \mathrm{H} 2 \mathrm{O}$ & 0.015 \\
$\mathrm{KH} 2 \mathrm{PO} 4$ & 0.5 \\
$\mathrm{~K} 2 \mathrm{HPO} 4$ & 0.5 \\
$\mathrm{pH}$ & 7 \\
\hline
\end{tabular}

\section{Agar well diffusion assay}

The agar well diffusion method was employed to determine the antibiotic production by the strain (20). Briefly the turbidity of 24 hours old cultures of test strains (S. aureus and M. luteus) was adjusted to 0.5 McFarland turbidity standard. The test strains was then applied on the surface of Muller Hinton agar plates $(30 \mathrm{ml})$ using sterilized cotton swab and allowed to dry for 15 minutes. Wells were made by using sterilized cork borer $(8 \mathrm{~mm})$. About $100 \mu$ l of the cell-free culture supernatants was transferred into each well. The agar plates were then incubated at required temperatures and observed for the development of zones of inhibitions around each well (Fig 1).

\section{Identification of Bacillus specie}

The strain producing maximum zones of inhibition was identified both morphologically and biochemically (5) as Bacillus specie (Table 2). The results were later confirmed by API 20E. 
Table 2. Biochemical Tests for Identification of Bacillus spp.

\begin{tabular}{cc}
\hline Test & Result \\
\hline Catalase & -ve \\
TSIA & $-\mathrm{ve}$ \\
SCA & $+\mathrm{ve}$ \\
Motility & $+\mathrm{ve}$ \\
Indole production & $-\mathrm{ve}$ \\
Oxidase & $+\mathrm{ve}$ \\
Starch hydrolysis & $+\mathrm{ve}$ \\
Gas production & $+\mathrm{ve}$ \\
MacConkey agar & Light pink \\
Eosin methylene blue & Colorless \\
Gram staining & $+\mathrm{ve}$ \\
Shape & Rod \\
negapore formation & $+\mathrm{ve}$ \\
\hline +ve positive &
\end{tabular}

\section{Identification of peptide antibiotics by paper chromatography}

The antibiotic produced by Bacillus strain was identified by bioautography (16) using Whatman No. 1 filter paper. Briefly the supernatant of each sample was applied separately 2 cm above the base of the paper and dried thoroughly. Afterwards the filter paper was dipped in the solvent system (acetone: acetic acid: water; 50:3:47). After the solvent migration till the end of the paper $(16-24 \mathrm{~cm})$, the chromatogram was air-dried by exposure to hot air with air drier. The developed papers were placed for 30 minutes on Muller Hinton agar inoculated with S. aureus and M. luteus, and the plates were then incubated at desired temperature and time. Finally the antibiotic was identified by measuring the Rf value (Retardation factor i.e the ratio of the distance traveled by the center of a spot to the distance traveled by the solvent front) and comparing it with $\mathrm{Rf}$ values of different antibiotics (23). Autobiography procedure was repeated for standard bacitracin purchased commercially (Oxoid).

\section{Optimization of various parameters for maximum} antibiotic production

For the optimization of microbial growth various parameters like time of incubation (up to 192 hours), the $\mathrm{pH}$ (4, 5, 6, 7 and 8) and the glucose concentration (2, 3, 4, 5 and 6\%) were determined (in triplicate) and results were recorded.

\section{RESULTS}

\section{The bacterial strain and peptide antibiotic identification}

About 112 different soil samples were screened for presence of peptide antibiotics producing bacteria. Of them, the strain GU 057 was selected for further screening seeing that this strain presented widest zones of inhibitions (18mm) against test strains (Fig 1). The strain GU057 was isolated from saline soil in the roots of Terminalia Arjuna roots in District D.I.Khan at $\mathrm{pH}$ 8.2. The strain was later identified as Bacillus sp. GU 057. The strain was subjected to batch fermentation and the samples were taken to identify the antibiotic by bioautography. The $\mathrm{Rf}$ values of the antibiotic produced by Bacillus spp was compared with standard antibiotic (bacitracin) $\mathrm{Rf}$ values and confirmed as bacitracin.

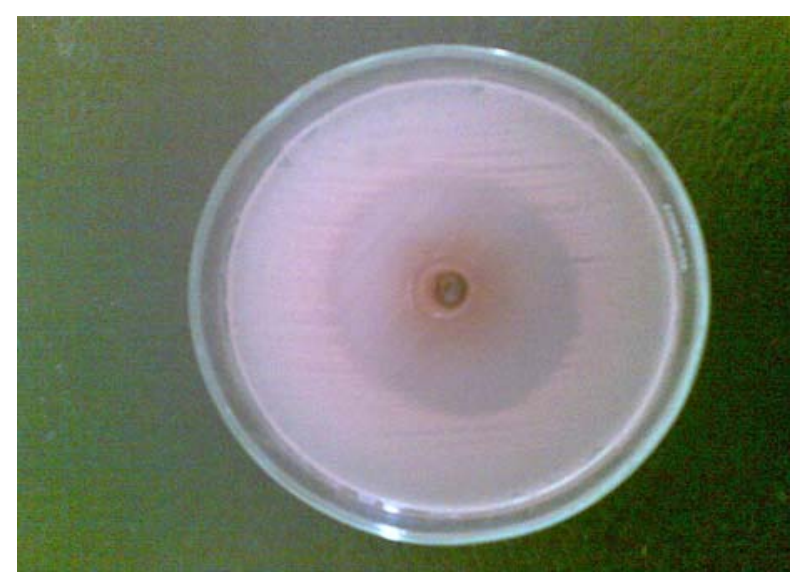

Figure 1. Widest zone of inhibitions (18mm) of Bacillus GU215 against Staphylococcus aureus

\section{Optimization of various parameters for antibiotic production}

Maximum activity of the bacitracin was observed after 48 hours of the incubation against Staphylococcus areus. Afterwards a steady decline in the activity was noted till 192 hours, while Micrococcus luteus presented comparatively lesser activity (Fig 2). 


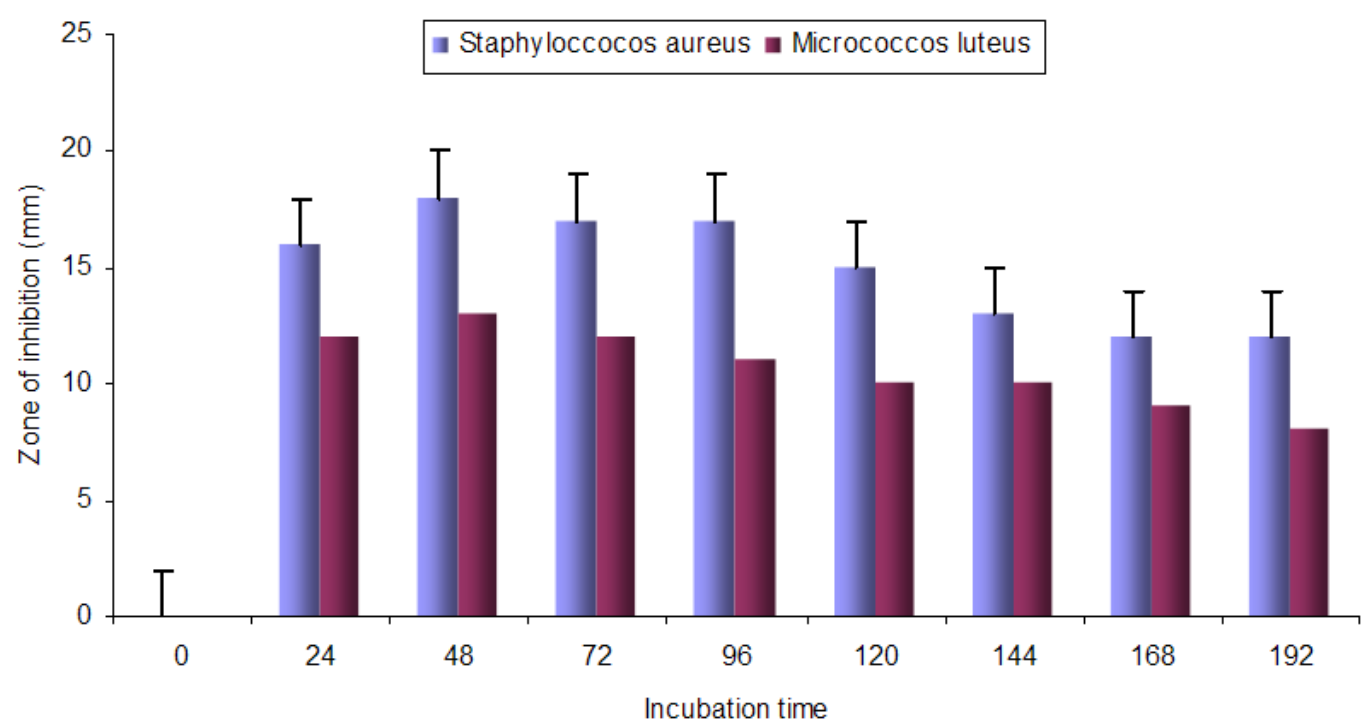

Figure 2. Development of inhibition zones produced by Bacillus spp.GU057 antibiotic against Staphylococcus aureus and Micrococcus luteus at different incubation time.

A gradual increase in the activity of the bacitracin was observed by increasing the glucose concentration and maximum inhibitory zone was recorded at $4 \%$ concentration of the glucose but after wards a decline in the activity was noted (Fig 3). Like wise maximum activity was observed at $\mathrm{pH} 8$ after 48 hours of incubation. Comparatively lesser activities were bacitracine was observed at $\mathrm{pH} 4$ to $\mathrm{pH} 7$ (Fig 4). Similarly the effect of different temperatures $(30,35,40,45$, $50,55^{\circ} \mathrm{C}$ ) on the production of antimicrobial in fermentation broth highlighted a maximum activity at $40^{\circ} \mathrm{C}$ (Fig 5).

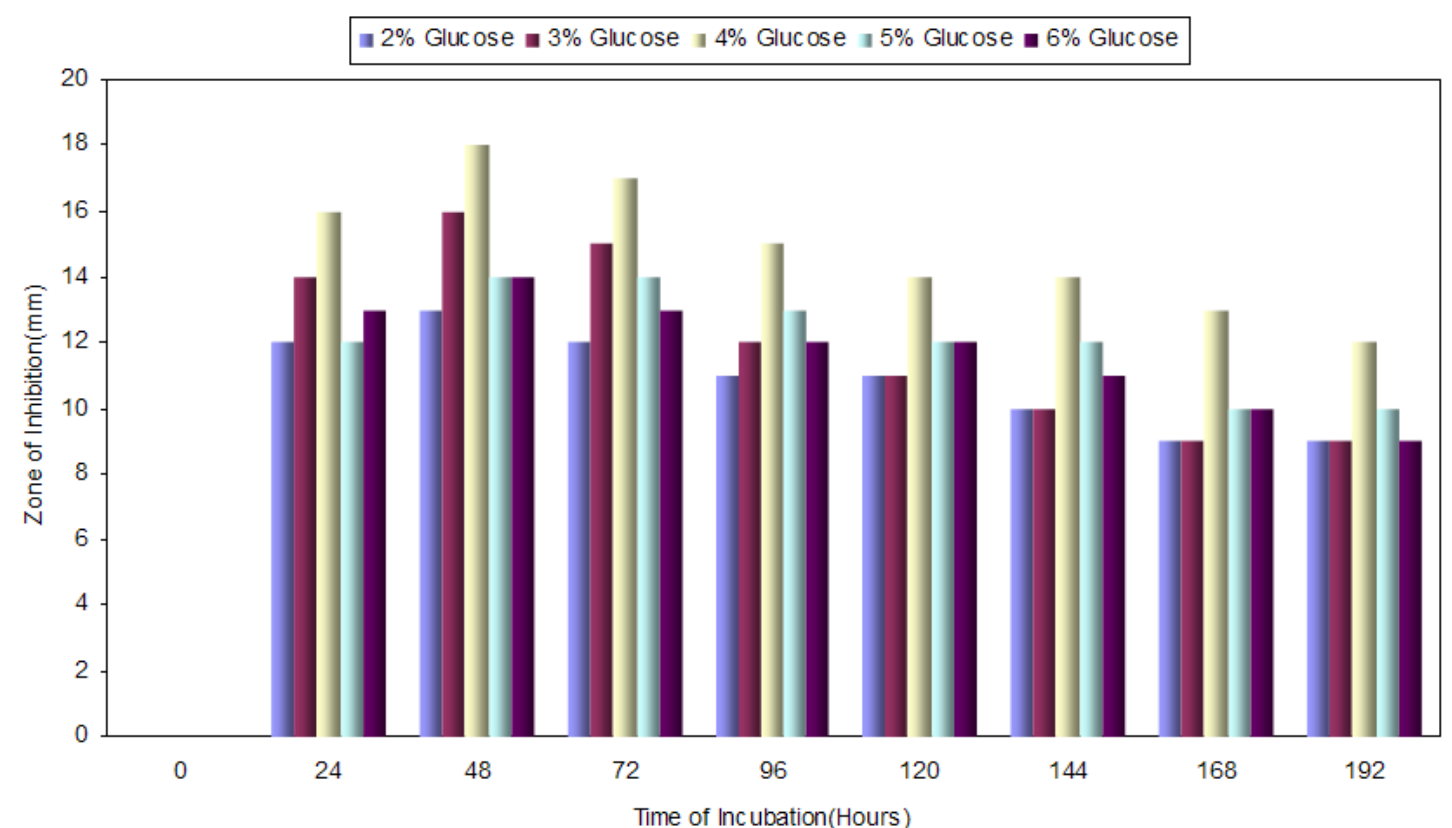

Figure 3. The effect of increasing glucose concentration on the zone of inhibition produced by Bacillus spp.GU057 against Staphylococcus aureus. 


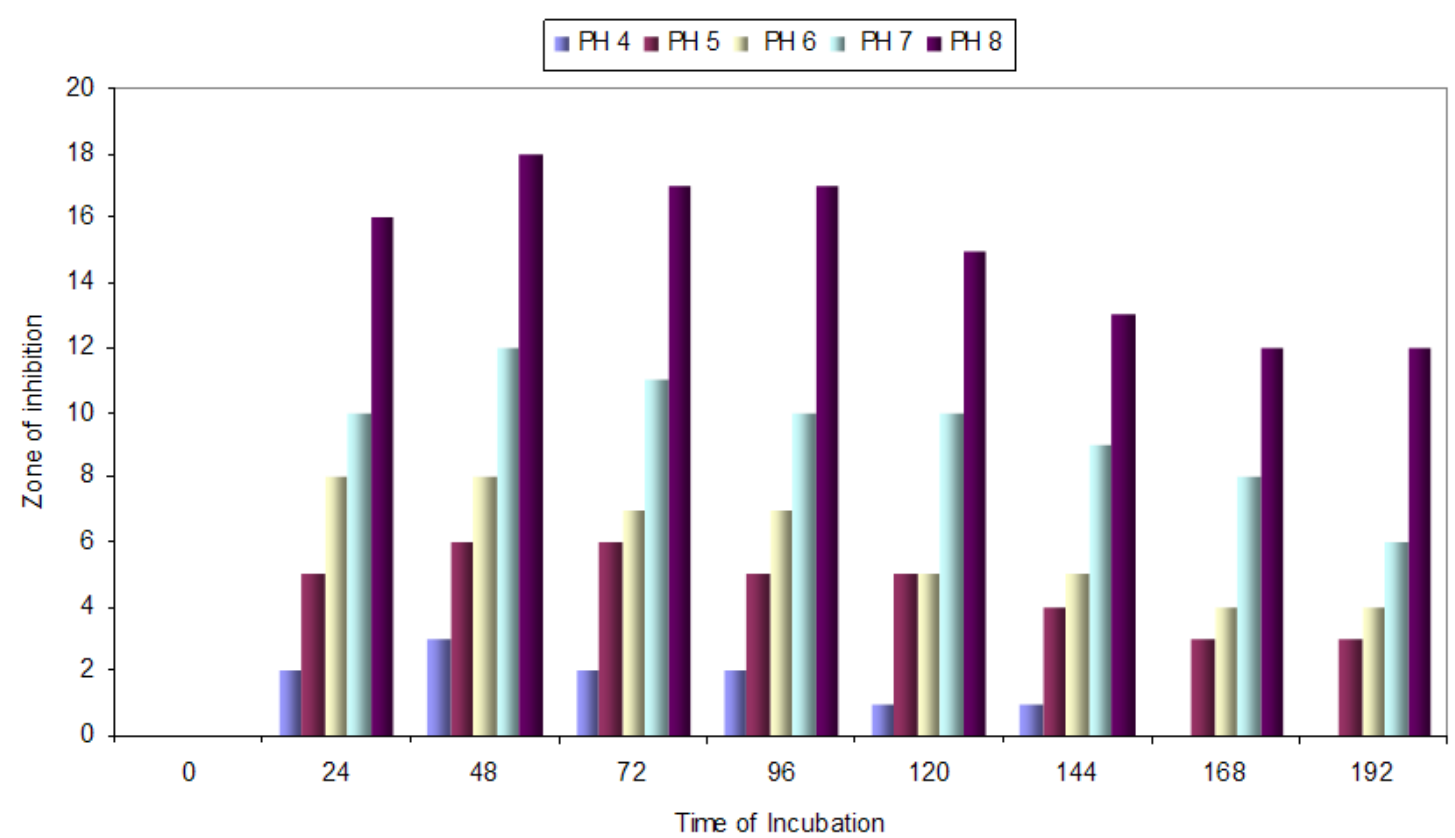

Figure 4. The effect of various $\mathrm{pH}$ levels on the zone of inhibition produced by Bacillus spp.GU057 against Staphylococcus aureus.

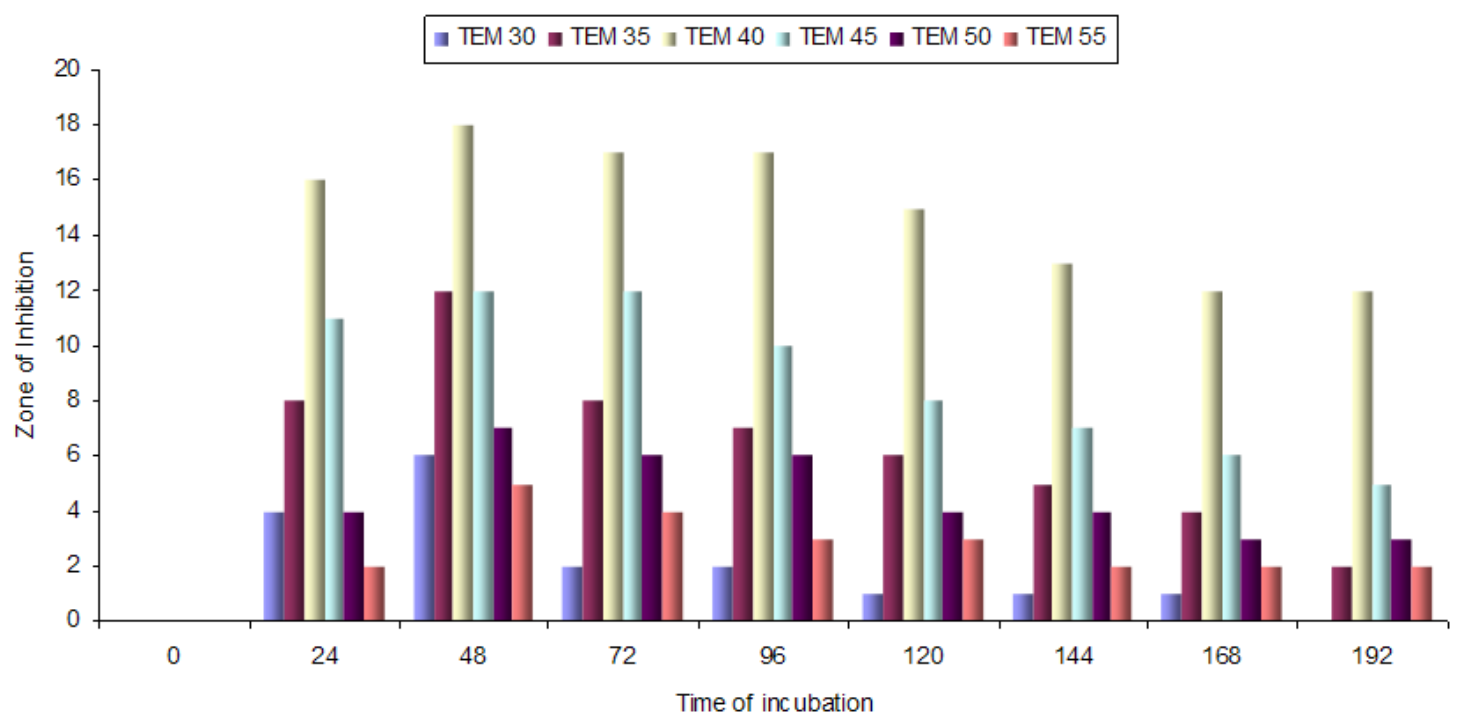

Figure 5. The effect of time of incubation on the zone of inhibition produced by Bacillus spp.GU057 against Staphylococcus aureus.

\section{DISCUSSION}

Soil is a prosperous source of microorganism that produces a wide range of antibiotics including peptide antibiotics $(2,14)$. The Bacillus species are most popular for producing peptide antibiotic compounds such as polymyxin, colistin, and circulin (15). The development of resistance and lesser safety margins provoked the scientist to search for antimicrobial agents with modified properties and maximum activity. With this background present study was conducted to 
assess the antibiotic production from bacillus species, identification of antibiotic and optimization of various growth parameters.

Among all soil samples collected from different areas of District D.I.Khan and Kohat, the strain GU 057 presented widest zones of inhibition against Staphylococcus aureus (18mm) followed by Microccos luteus (13mm) after 48 hours of incubation. This trend remained approximately same till 62 hour, however a gradual decline in the inhibition was observed as the time of incubation increased till 192 hours. This trend is supported by earlier findings $(1,2,16)$.

Glucose is an essentail nutrient required for the growth and production of secondary metabolites including the antibiotics (11). The strain GU 057 presented a steady increase in the zone of inhibition by increasing the concentration of glucose in the production media (16) and maximum activity was reported at $4 \%$ glucose concentration. Never theless a controlled decline in the activity was observed at higher glucose concentrations as have been described previously (11, 13).

The effect of temperature on the growth and secondary metabolites (antibiotics) synthesis was determined by incubating the strain GU 057 at various temperatures. The strain showed encouraging results at the $40^{\circ} \mathrm{C}$ after 48 hours of incubation. This may be the thermophilic nature of the strain $(1,12)$. Significantly lower levels of zones of inhibitions were observed at all other temperatures $\left(30,35,45,50\right.$ and $\left.55^{\circ} \mathrm{C}\right)$.

Similarly the effect of $\mathrm{pH}$ on zones of inhibition produced by Bacillus strain was not un surprising. The widest inhibitory zone was reported at $\mathrm{pH} 8$ after 48 hours of incubation. This activity is the result of extremophilic nature of the strain (saline soil) as reported earlier $(19,21)$. Comparatively much lesser inhibition was reported at $\mathrm{pH} \mathrm{4,5,6}$ and 7 as the time of incubation was increased from 49 to 192 hours as observed previously $(6,12)$. The results of present study confirm the Bacillus sp. GU 057 strain isolated from saline soil, as producer of peptide antibiotic (bactitracin).

\section{REFERENCES}

1. Ahmad, S.; Muhammad, S.U; Hameed, A. (2009). Antibiotic production by thermophilic Bacillus specie SAT-4 Pak. J. Pharm. Sci. 22(3), 339345.

2. Awais, M.; Pervez, A.; Qayyum, S.; Saleem, M.(2008). Effects of glucose, incubation period and $\mathrm{pH}$ on the production of peptide antibiotics by Bacillus pumilus. Afri. Jour. Microbiol. Res. 2, 114-119.

3. Babasaki, K.; Takao, T.; Shimonishi, Y.; Kurahashi, K.; Subtilosin, A. (1985) a new antibiotic peptide produced by Bacillus subtilis 168: isolation, structural analysis, and biogenesis. J. Bio Chem. 98(3), 585603.

4. Berdy, J. (1980). Recent advances in and prospects of antibiotic research. Process Biochem. 15: 28-36.

5. Bergey, D.H.; Holt, J.G.; (1994). In: Bergey's Manual of Determinative Bacteriology. 9th ed. Williams \& Wilkins Publishers, Baltimore.

6. Bushra, J.; Hasan, F.; Hameed, A.; Ahmed, S. (2007). Isolation of Bacillus subtilis MH-4 from soil and its potential of polypeptidic antibiotic production. Pak. J. Pharm. Sci., 20(1), 26-31.

7. Cherif, A.; Chehimi, S.; Limem, F. (2003). Detection and characterization of the novel bacteriocin entomocin 9, and safety evaluation of its producer, Bacillus thuringiensis ssp. Entomocidus HD9. Appl. Microbiol. 95, 990-1000.

8. Cherif, A,; Ouzari, H.; Daffonchio, D. (2001). Thuricin 7 a novel bacteriocin produced by Bacillus thuringiensis BMG1.7, a new strain isolated from soil. Lett. Appl. Microbiol. 32, 243-247.

9. Demain, A.L.; Aharonowitz, Y.; Martin, J.F. (1983). Metabolite control of secondary biosynthetic pathways. In: Vining LC (Ed.), Biochemistry and Genetic Regulation of Commercially Important Antibiotics. Addison-Wesley, London, pp.49-67

10. Emmert, E.A.B,; Handelsman, J. (1999). Biocontrol of plant disease; a (Gram- positive perspective). F.E.M.S. Microbiol. Lett. 17, 1-9.

11. Espeso, E.A.; Tilburn, J.; Arst, H.N.; Peñalva, M.A. (1993). pH regulation is a major determinant in expression of a fungal penicillin biosynthetic gene. E.M.B.O. J., 12, 3947-3956.

12. Esikova, T.Z.; Temirov, Y.V.; Sokolov, S.L.; Alakhov, Y.B. (2002). Secondary Antimicrobial Metabolites Produced by Thermophilic Bacillus spp. Strains VK2 and VK21. Appl. Biochem. Microbiol. 38, 226-231.

13. Gesheva, V.; Ivanova, V.; Gesheva, R. (2005). Effects of nutrients on the production of AK-111-81 macrolide antibiotic by Streptomyces hygroscopicus. Microbiol. Reds., 160: 243-248.

14. Janabi, A.A.H. (2006). Identification of Bacitracin Produced by Local Isolate of Bacillus licheniformis. Afr. J. Biotechnol. 5 (18): 1600-1601.

15. Katz, E.; Demain, A.L. (1997). The peptide antibiotics of Bacillus, chemistry, biogenesis, and possible functions. Bacteriol Rev., 41: 449474. 
16. Mendo, S.; Faustino, N.A.; Sarmento, A.C.; Amado, F.; Moir, A.J.(2004). Purification and characterization of a new peptide antibiotic produced by a thermotolerant Bacillus licheniformis strain. Biotechnol. Lett. 26, 115-119

17. Nakano, M.M.; Zuber, P. (1990). Molecular biology of antibiotic production in Bacillus. Crit. Rev. Biotechnol. 10(3):223-240.

18. Paik, S.H.; Chakicherla, A.; Hansen, J.N.( 1998). Identification and characterization of the structural and transporter genes for, and the chemical and biological properties of, sublancin 168, a novel lantibiotic produced by Bacillus subtilis 168. J. Biol. Chem. 273(36), 23134-23142.

19. Priest, F.G. (1992). Biology of Bacilli. In: Bacilli applications to industry. Edited by Doi RH and McGloughlin M. ButterworthHeinemann, Boston, Mass, pp.293-320.

20. Sen, K.S., Haque, F.S.; Pal, C.S. (1995). Nutrient optimization for production of broad spectrum antibiotics by Streptomyces antibioticus Str. 15.4. Acta. Microbial. Hung. 42:155-162.

21. Schallmey, M., Singh, A.; Ward, O.P. (2004). Developments in the use of Bacillus species for industrial production. Can. J. Microbial., 50: 117.

22. SiloSuh, L.A.; Lethbridge, B.J.; Raffel, S.J.; He, H.; Clardy, J.;
Handelsman, J.(1994). Biological activities of two fungistatic antibiotics produced by Bacillus cereus UW85. Appl. Environ. Microbiol. 60(6), 2023-2030.

23. Snell, N.; Ijichi, K.; Lewis, J.C. (1956). Paper Chromatographic Identification of Polypeptide Gram Positive Inhibiting Antibiotics. Appl. Microbiol. 4(1): 13-17.

24. Stover, A.G.; Driks, A. (1999). Secretion, localization, and anti-bacterial activity of TasA, a Bacillus subtilis spore-associated protein. J. Bacteriol. 181(5), 1664-1672.

25. Yousaf, M. (1997). Studies on the cultural conditions for the production of antibiotic bacitracin by $B$. licheniformis. $\mathrm{PhD}$ dissertation, Islamia University, Bahawalpur, Pakistan. (http://eprints.hec.gov.pk/view/subjects/f2.html).

26. Zinsser, H. (1988). Antimicrobial agents, 9th chapter. In: Zinsser H, Joklik WK, Willett HP, Amos DB, Wilfert C (ed.), Zinsser Microbiology, Prentice Hall International, UK, pp.128-160.

27. Zhang, Y. (2004). Biocontrol of sclerotinia stem rot of canola by bacterial antagonists and study of biocontrol mechanisms in-volved. M.Sc. thesis, University of Manitoba, Winnipeg, Manitoba. 